Article

\title{
Variable Angle Spectroscopic Ellipsometry Characterization of Reduced Graphene Oxide Stabilized with Poly(Sodium 4-Styrenesulfonate)
}

\author{
Grazia Giuseppina Politano ${ }^{1, *}$, Carlo Vena ${ }^{1}$, Giovanni Desiderio ${ }^{2}$ and Carlo Versace ${ }^{1,2}$ (1) \\ 1 Dipartimento di Fisica, Università della Calabria, 87036 Rende CS, Italy; carlo.vena@fis.unical.it (C.V.); \\ carlo.versace@fis.unical.it (C.V.) \\ 2 Licryl CNR/Nanotec c/o Dipartimento di Fisica, Università della Calabria, 87036 Rende CS, Italy; \\ giovanni.desiderio@fis.unical.it \\ * Correspondence: grazia.politano@unical.it
}

Received: 1 July 2020; Accepted: 27 July 2020; Published: 29 July 2020

\begin{abstract}
Lately, the optical properties of Graphene Oxide (GO) and Reduced Graphene Oxide (RGO) films have been studied in the ultraviolet and visible spectral range. However, the accurate optical properties in the extended near-infrared and mid-infrared range have not been published yet. In this work, we report a Variable Angle Spectroscopic Ellipsometry (VASE) characterization of GO thin films dip-coated on $\mathrm{SiO}_{2} / \mathrm{Si}$ substrates and thermally reduced GO films in the 0.38-4.1 eV photon energy range. Moreover, the optical properties of RGO stabilized with poly(sodium 4-styrenesulfonate) (PSS) films dip-coated on $\mathrm{SiO}_{2} / \mathrm{Si}$ substrates are studied in the same range for the first time. The Lorentz optical models fit well with the experimental data. In addition, the morphological properties of the samples were investigated by Scanning Electron Microscopy (SEM) analysis.
\end{abstract}

Keywords: graphene oxide; ellipsometry; optical properties; reduced graphene oxide; PSS

\section{Introduction}

Graphene Oxide (GO) reduction is a promising approach for the mass production of graphene [1] and the product obtained by this method is known as Reduced Graphene Oxide (RGO). RGO is obtained by means of chemical methods [2], which are used to remove or decrease the oxygen-containing groups. Other reduction methods include thermal annealing, which is usually achieved above $200{ }^{\circ} \mathrm{C}[3]$ and is eventually more effective at higher temperatures, and "green reducers" such as ascorbic acid, plants, biochemical substances, amino acids, etc. [4].

GO [5] and RGO have been used in several applications such as the electrochemical properties [6] and anti-corrosion properties [7,8] enhancement, oligonucleotide detection [9], improvement of chitosan-gelatin biocomposite films [10] and Urethane-Acrylate Transparent Coatings [11], Molecular Dynamics Simulations of DNA Adsorption [12].

Unfortunately, unmodified RGO is hydrophobic and has a tendency to agglomerate or restack to form graphite by Van der Waals interactions and strong $\pi-\pi$ stacking in aqueous solutions [13], damaging thus the advantage of the high surface area and the great single-layer electrical properties of graphene [14].

Surface functionalization is an effective way to hinder the aggregation of RGO. Two approaches are used for modifying the GO surface: Covalent functionalization and non-covalent modification [15].

Non-covalent functionalization is obtained using polymer wrapping, adsorption of surfactants or small molecules via $\pi-\pi$ stacking interactions, avoiding thus surface defects and disruption of electron conjugation of graphene [15]. Among non-covalent functionalization methods, an interesting 
case is the surface functionalization of RGO with poly(sodium 4-styrenesulfonate) (PSS). PSS is a polyelectrolyte used as a spacer to avoid RGO agglomeration [16], it is non-toxic, water soluble, and it interacts with graphene through $\pi-\pi$ interaction. In addition, the polymer of PSS is able to provide more 2D aromatic planes to RGO, increasing its drug loading efficiency for biological applications [17].

PSS-RGO composites evidence great stability and electrocatalytic activities, efficient electron transfer, and high conductivity [18]. The capacitance performance, electrochemical and biological properties of PSS-RGO composites have been investigated by other groups $[16,19,20]$. Despite this, the optical constants of PSS-functionalized RGO films have not been studied yet.

Access to precise complex refractive index data is central for the design of GO and RGO-based optical materials. The optical constants are important because they govern the reflection, transmission, and absorption of light [21]. One method to study the refractive index and the extinction coefficient of a material is Spectroscopic Ellipsometry (SE) [21], which is an high accurate optical technique used for investigating the optical properties of materials. In our previous works we have studied graphene-based materials by means of Variable Angle Spectroscopic Ellipsometry (VASE) [22-25]. SE measures the complex ratio $\rho$ [26] as a function of wavelength while VASE [27] performs the above measurement as a function of both wavelength and angle of incidence.

In the present study, the optical properties of PSS-functionalized RGO films dip-coated on $\mathrm{SiO}_{2} / \mathrm{Si}$ substrates were studied by VASE in the photon energy range between 0.38 and $4.1 \mathrm{eV}$. In addition, the optical properties of GO and thermally reduced GO films were reported in the same range. The complex refractive index of GO and RGO have been determined by SE, especially in the ultraviolet and visible range $[24,28,29]$. However, SE characterization of GO and RGO films in the extended near-infrared and mid-infrared range remains yet unexplored because of the standard ellipsometry equipment limitations. We have carried out VASE measurements from ultraviolet to mid-infrared range.

The results of the present study may be useful for material design based on aqueous GO and PSS-RGO dispersion. Our study could be important for specific applications, such as hyperbolic metamaterials [30] and gas sensors in the mid-infrared [31] range, metamaterials assembled in microfluidic channels [32], and photodetectors in the near-infrared [33] range.

\section{Materials and Methods}

$\mathrm{N}$-type $\mathrm{SiO}_{2} / \mathrm{Si}$ wafers (resistivity $>5000 \mathrm{ohm} \cdot \mathrm{cm}$ ) were bought from Siltronic. The wafers, which were used as substrates, were ultrasonically cleaned in acetone, then in double-distilled water and isopropanol. Finally, they were dried with warm air.

The dip-coating process [34] was employed to deposit GO and PSS-functionalized RGO on $\mathrm{SiO}_{2} / \mathrm{Si}\left(\mathrm{SiO}_{2} \sim 2 \mathrm{~nm}\right)$ substrates with a homemade apparatus at a speed of $0.33 \mathrm{~mm} / \mathrm{s}$. The samples were prepared using commercial dispersions in $\mathrm{H}_{2} \mathrm{O}$ of $\mathrm{GO}(4 \mathrm{mg} / \mathrm{mL})$ and PSS-functionalized RGO $(10 \mathrm{mg} / \mathrm{mL})$ that were bought from Sigma-Aldrich. The solutions were sonicated for $30 \mathrm{~min}$ using an ultrasonic bath.

$\mathrm{GO}$ films on $\mathrm{SiO}_{2} / \mathrm{Si}$ were eventually heated at $400{ }^{\circ} \mathrm{C}$ for $20 \mathrm{~min}$ in an $\mathrm{Ar}$ atmosphere furnace. It is worth noticing that in our previous work [24] we have demonstrated the reduction of GO films by thermal annealing at $400{ }^{\circ} \mathrm{C}$.

SEM analysis was accomplished with a FEI Quanta FEG 400 F eSEM microscope (Eindhoven, The Netherlands). The images were acquired at a potential of $15.0 \mathrm{KV}$ using an Everhart-Thornley detector (ETD).

The optical characterization of the samples was carried out by using VASE. Spectra of the ellipsometric angles $\psi$ and $\Delta$ were acquired using a V-Vase (J.A. Woollam, Lincoln, NE, USA) ellipsometer in the $0.38-4.1 \mathrm{eV}$ photon energy range at 65,70 , and $75^{\circ}$ incident angles at room temperature. These angles were chosen because VASE measurements are usually done around the Brewster's angle air-substrate, which for silicon is about $65^{\circ}$, to have a better contrast. The depolarization factor in all spectra was less than $10 \%$ and thus it was neglected. The optical model and the best fitting values were calculated by WVASE32 (J.A. Woollam, Lincoln, NE, USA) application by means of the 
nonlinear Levenberg-Marquardt algorithm, which determines the minimum value of the Mean Square Error (MSE) [21].

\section{Results and Discussion}

\subsection{Scanning Electron Microscopy Measurements}

Figures 1 and 2 show topographic SEM images of GO and thermally reduced GO films on $\mathrm{SiO}_{2} / \mathrm{Si}_{\text {, }}$ respectively. Figures 1 and 2 were acquired using a working distance of $10.1 \mathrm{~mm}$.

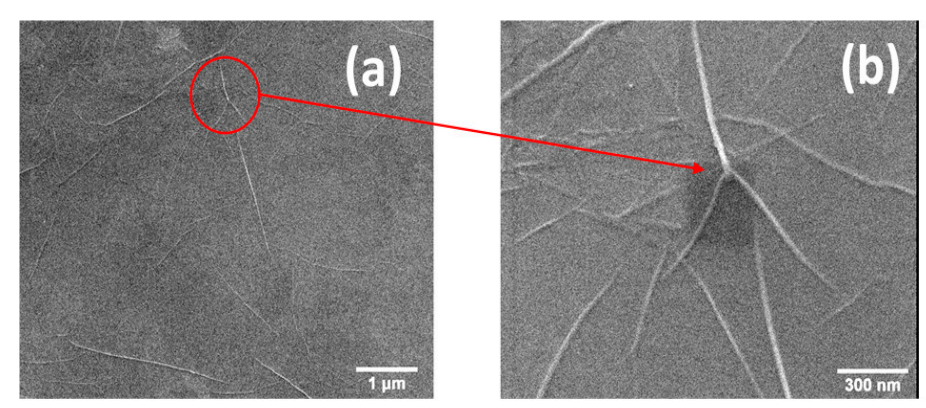

Figure 1. Scanning electron microscopy image of graphene oxide films on $\mathrm{SiO}_{2} / \mathrm{Si}$ substrates (a) and related magnification $(\mathbf{b})$.
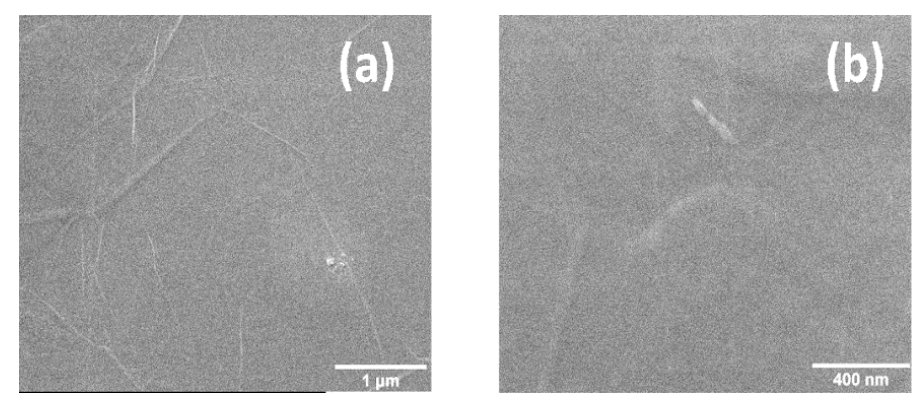

Figure 2. Scanning electron microscopy image of thermally reduced graphene oxide films on $\mathrm{SiO}_{2} / \mathrm{Si}$ substrates (a) and related magnification (b).

Figure 1a highlights that the GO film covers the whole surface uniformly. A low surface roughness is noted at higher magnifications in Figure $1 b$. In the same figure wrinkles that do not cause surface breakages are visible, as reported in previous works [35]. The lack of film breakage could indicate a considerable intrinsic elasticity and a strong adhesion to the underlying surface.

The topology of the samples does not change upon heating, as it is visible in Figure 2.

In Figure 3 topographic SEM images of PSS-functionalized RGO films on $\mathrm{SiO}_{2} / \mathrm{Si}$ substrates are reported. Figure $3 \mathrm{a}, \mathrm{b}$ was acquired using a working distance of 10.0 and $9.9 \mathrm{~mm}$, respectively.

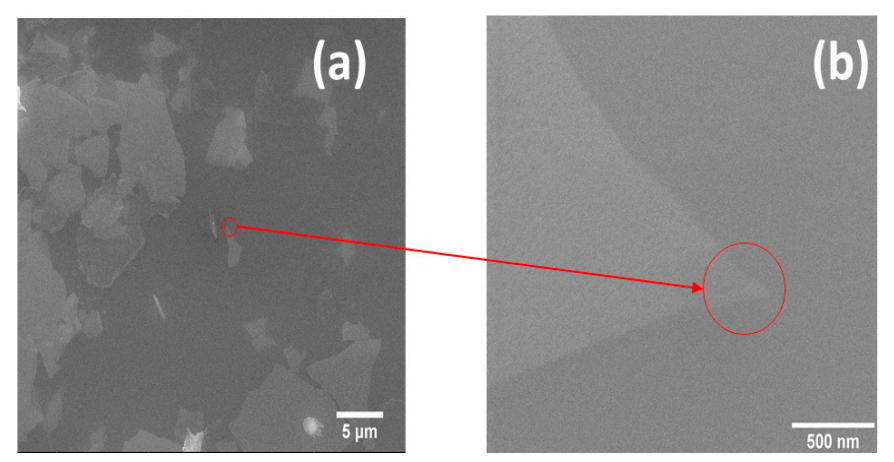

Figure 3. Scanning electron microscopy image of reduced graphene oxide films stabilized with poly(sodium 4-styrenesulfonate) (PSS) on $\mathrm{SiO}_{2} / \mathrm{Si}$ substrates (a) and related magnification (b). 
Figure 3a highlights that the PSS-functionalized RGO film covers the whole surface, though not uniformly. In fact there are fragments of film with uneven sections, which indicate the detachment of the film from the surface and the subsequent overlap. At higher magnifications in Figure $1 \mathrm{~b}$ a certain surface porosity is detected.

\subsection{Variable Angle Spectroscopic Ellipsometry Measurements}

We estimated the optical model of the substrates using the models implemented in the WVASE32 software [36].

In Figures 4 and 5 the experimental and generated values of $\psi(a)$ and $\Delta$ (b) for GO and thermally reduced GO films on $\mathrm{SiO}_{2} / \mathrm{Si}$ substrates are reported at different angles of incidence in the $0.38-4.1 \mathrm{eV}$ photon energy range, respectively. An excellent agreement between the model generated data (circles) and experimentally acquired data (solid lines) is observed in Figures 4 and 5.
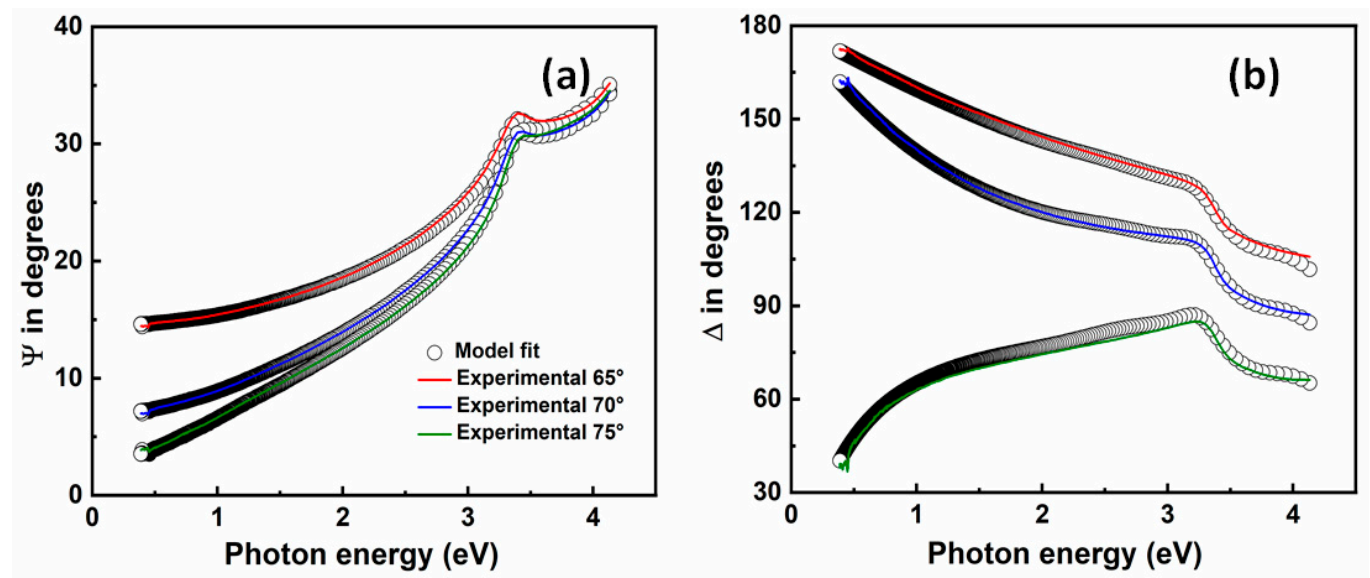

Figure 4. Variable angle spectroscopic ellipsometry measurements of graphene oxide films on $\mathrm{SiO}_{2} / \mathrm{Si}$ substrates. Experimental and model generated $\psi(\mathbf{a})$ and $\Delta(\mathbf{b})$ data fits at different angles of incidence.
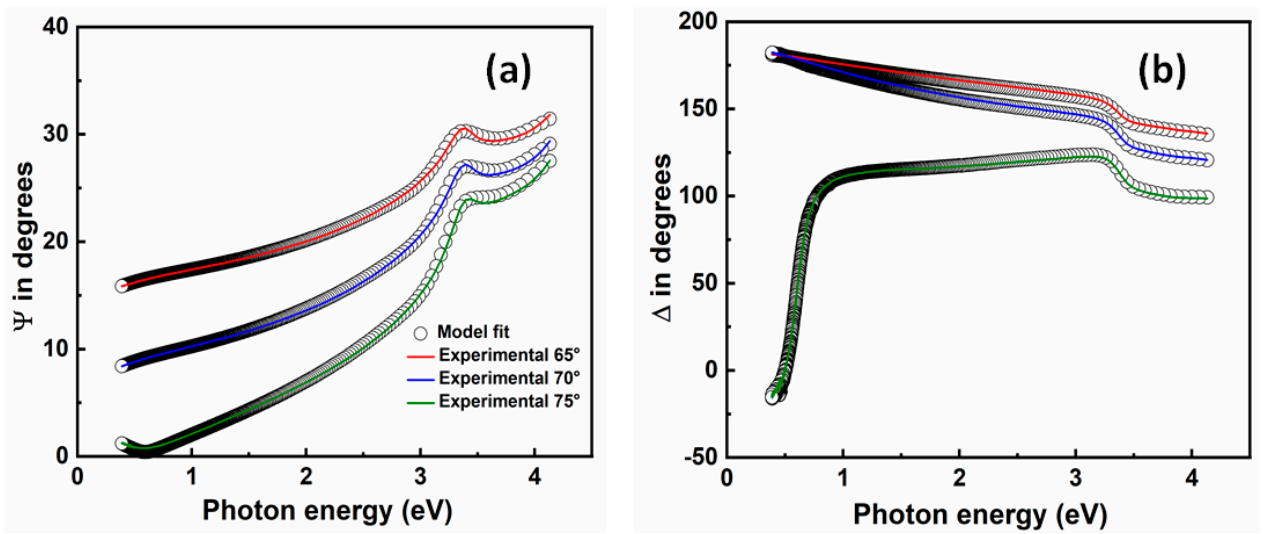

Figure 5. Variable angle spectroscopic ellipsometry measurements of thermally reduced graphene oxide films on $\mathrm{SiO}_{2} / \mathrm{Si}$ substrates. Experimental and model generated $\psi(\mathbf{a})$ and $\Delta(\mathbf{b})$ data fits at different angles of incidence.

GO and thermally reduced GO films were modeled as the sum of Lorentz oscillators to keep consistency with the Kramers-Kronig relations [37]. The complex dielectric function is characterized by the relation:

$$
\widetilde{\varepsilon}(h v)=\varepsilon_{1}+i \varepsilon_{2}=\varepsilon_{\infty}+\sum_{k=1}^{N} \frac{A_{k}}{E_{k}^{2}-E^{2}-i \Gamma_{k} E}
$$


where $E$ is the energy of the incident photons, $\varepsilon_{\infty}$ is the real part of the dielectric function when $E \rightarrow \infty$, $A_{k}$ is the strength expressed in $\mathrm{eV}^{2}, \Gamma_{k}$ is the broadening in $\mathrm{eV}$, and $E_{k}$ is the central energy of the $k$-th oscillator. $A_{k}$ also indicates the contribution of each oscillator $k$ to the whole system.

Table 1 shows the parameters from the best fit with a low MSE for GO and thermally reduced GO films on $\mathrm{SiO}_{2} / \mathrm{Si}$ substrates. The models provide excellent data fittings with a MSE 3.

Table 1. Lorentz oscillators parameters for graphene oxide and thermally reduced graphene oxide films on $\mathrm{SiO}_{2} / \mathrm{Si}$. Amplitude $A_{k}$ has a unit of $\mathrm{eV}^{2}$, center energy $E_{k}$ and broadening $\Gamma_{k}$ have units of eV; $d$ is the thickness of film in nm; the high-frequency dielectric constant $\varepsilon_{\infty}$ is dimensionless.

\begin{tabular}{cccc}
\hline & GO & \multicolumn{2}{c}{ rGo } \\
\hline$d(\mathrm{~nm})$ & $19 \pm 1$ & $d(\mathrm{~nm})$ & $18 \pm 1$ \\
$\varepsilon_{\infty}$ & $1.62 \pm 0.04$ & $\varepsilon_{\infty}$ & $1.01 \pm 0.01$ \\
$A_{1}\left(\mathrm{eV}^{2}\right)$ & $1.8 \pm 0.2$ & $A_{1}\left(\mathrm{eV}^{2}\right)$ & $1.7 \pm 0.2$ \\
$\Gamma_{1}(\mathrm{eV})$ & $1.05 \pm 0.09$ & $\Gamma_{1}(\mathrm{eV})$ & $10.0 \pm 3.6$ \\
$E_{1}(\mathrm{eV})$ & $2.8 \pm 0.1$ & $E_{1}(\mathrm{eV})$ & $2.1 \pm 0.4$ \\
$A_{2}\left(\mathrm{eV}^{2}\right)$ & $7.0 \pm 0.2$ & $A_{2}\left(\mathrm{eV}^{2}\right)$ & $13.5 \pm 0.3$ \\
$\Gamma_{2}(\mathrm{eV})$ & $0.69 \pm 0.05$ & $\Gamma_{2}(\mathrm{eV})$ & $0.39 \pm 0.02$ \\
$E_{2}(\mathrm{eV})$ & $3.22 \pm 0.01$ & $E_{2}(\mathrm{eV})$ & $3.17 \pm 0.03$ \\
$A_{3}(\mathrm{eV})$ & $2.3 \pm 0.1$ & $A_{3}(\mathrm{eV})$ & $14.3 \pm 0.3$ \\
$\Gamma_{3}(\mathrm{eV})$ & $0.59 \pm 0.08$ & $\Gamma_{3}(\mathrm{eV})$ & $2.05 \pm 0.04$ \\
$E_{3}(\mathrm{eV})$ & $3.90 \pm 0.02$ & $E_{3}(\mathrm{eV})$ & $4.02 \pm 0.02$ \\
\hline
\end{tabular}

As it can be seen in Table 1, the behavior of the dispersion laws of GO and thermally reduced GO films is described by three Lorentz oscillators.

In the GO optical model, oscillator 1 at $\sim 2.8 \mathrm{eV}$ denotes different coverage of mixed hydroxyl groups and oxygen atoms $[28,38]$. Oscillator 2 at $\sim 3.2 \mathrm{eV}$ (at $\sim 388 \mathrm{~nm}$ ) represents a transition that is near the shoulder in the absorbance spectrum of GO (at $\sim 320 \mathrm{~nm}$ ) and close to the wavelength of blue luminescence detected for partially RGO (at $\sim 390 \mathrm{~nm}$ ) [39]. Oscillator 3 at $\sim 3.9 \mathrm{eV}$ is assigned to the small shoulder of GO in the absorbance spectrum [39].

In the RGO optical model, oscillator 1 at $\sim 2.1 \mathrm{eV}$ denotes different coverage of mixed hydroxyl groups and oxygen atoms [28]. Oscillator 2 at $\sim 3.17 \mathrm{eV}$ may be related to the narrow photoluminescence peak observed for partially RGO [39]. Eda et al. [40] reported excitonic features observable on RGO films between 4 and $4.4 \mathrm{eV}$, which are the absorption energies corresponding to the emission of blue light. Oscillator 3 at $\sim 4 \mathrm{eV}$ falls in that range. This blue photoluminescence has been explained considering that the existence of isolated $\mathrm{sp}^{2}$ clusters inside the carbon-oxygen $\mathrm{sp}^{3}$ matrix creates the localization of $e-h$ pairs, enabling thus the radiative recombination of small clusters [40].

Figure $6 \mathrm{a}, \mathrm{b}$ shows the dispersion laws, estimated by ellipsometry characterization in the $0.38-4.1 \mathrm{eV}$ photon energy range, of $\mathrm{GO}$ and thermally reduced $\mathrm{GO}$ films on $\mathrm{SiO}_{2} / \mathrm{Si}$ substrates.
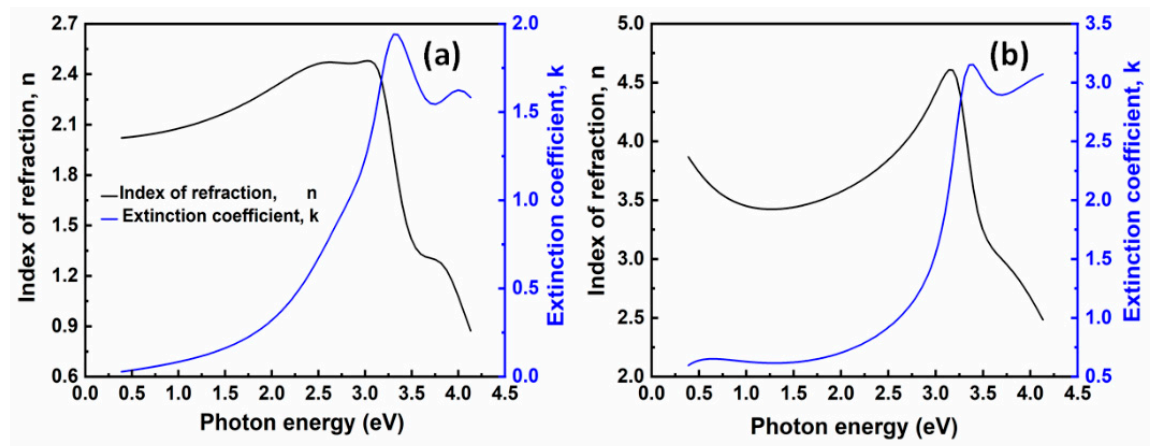

Figure 6. Estimated dispersion laws estimated of graphene oxide (a) and thermally reduced graphene oxide (b) films on $\mathrm{SiO}_{2} / \mathrm{Si}$ substrates by ellipsometry characterization. The curves represent the index of refraction (black lines) and the extinction coefficient (blue lines). 
The derived refractive indices and extinction coefficients of GO and thermally reduced GO films agree well with our previous research works $[23,24]$.

The high index of refraction and transparency over the visible spectral range of these GO and thermally reduced GO films could lead to several optoelectronic applications, for example, photodetectors and metamaterials.

As it can be seen in Figure 7, thermal annealing increases the optical conductivity of GO.
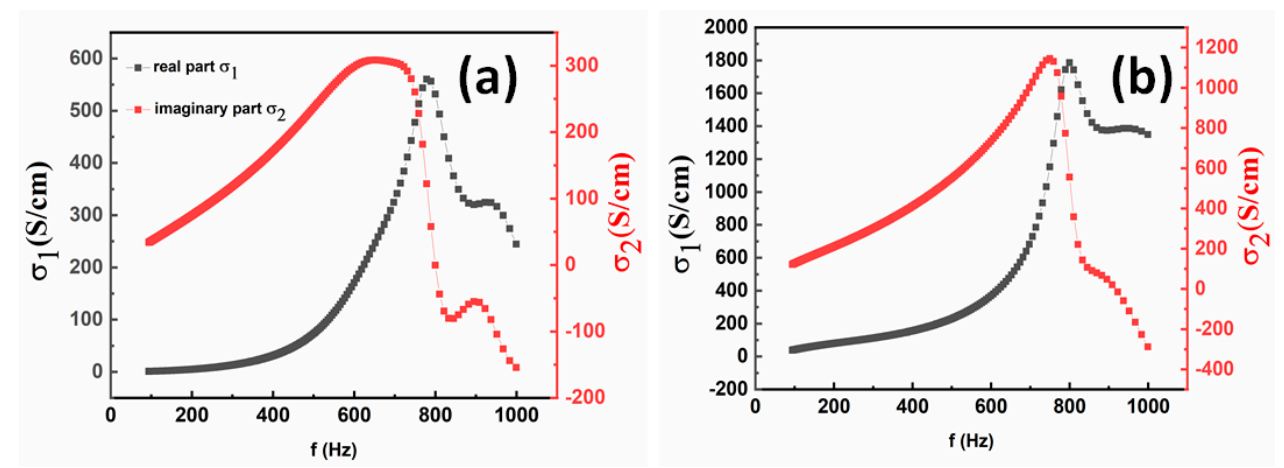

Figure 7. The optical conductivity dependence on frequency of graphene oxide (a) and thermally reduced graphene oxide (b) films on $\mathrm{SiO}_{2} / \mathrm{Si}$ substrates.

The complex optical conductivity $\sigma=\sigma_{1}+\sigma_{2}$ is related to the complex dielectric constant $\varepsilon=\varepsilon_{1}+\varepsilon_{2}$ by the following relations [41]:

$$
\sigma_{1}=\omega \varepsilon_{2} \varepsilon_{0} \text { and } \sigma_{2}=\omega \varepsilon_{1} \varepsilon_{0}
$$

where $\omega$ is the angular frequency, $\varepsilon_{0}$ is the free space dielectric constant.

In Figure 8 the experimental and generated values of $\psi(a)$ and $\Delta(b)$ for PSS-functionalized RGO films on $\mathrm{SiO}_{2} / \mathrm{Si}$ substrates are reported at different angles of incidence in the $0.38-4.1 \mathrm{eV}$ photon energy range. An excellent agreement between the model generated data (circles) and experimentally acquired data (solid lines) is observed in Figure 8.
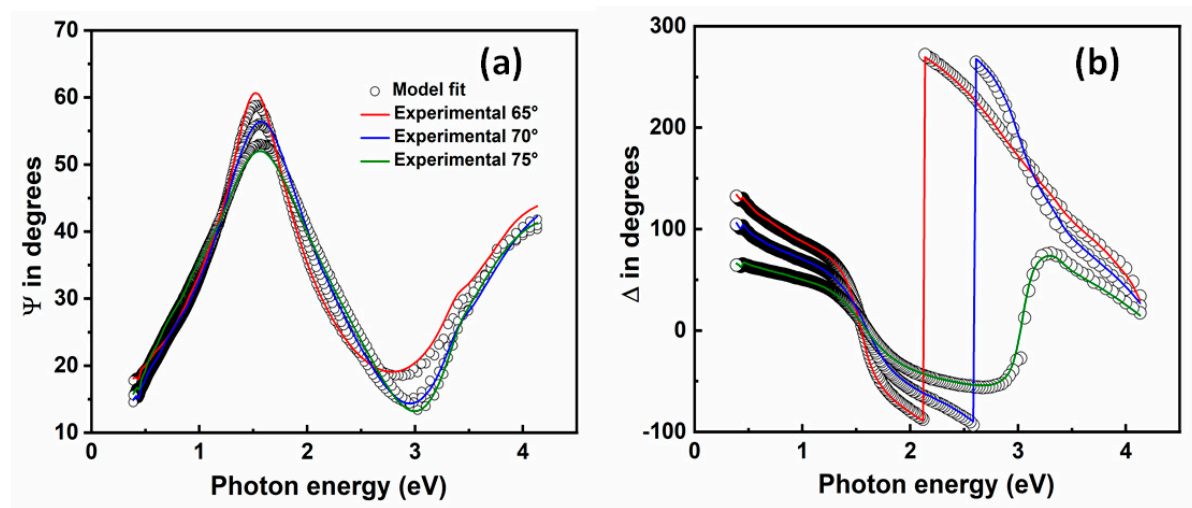

Figure 8. Variable angle spectroscopic ellipsometry measurements of reduced graphene oxide stabilized with poly(sodium 4-styrenesulfonate) on $\mathrm{SiO}_{2} / \mathrm{Si}$ substrates. Experimental and model generated $\psi$ (a) and $\Delta(\mathbf{b})$ data fits at different angles of incidence.

Table 2 shows the parameters from the best fit for PSS-functionalized RGO films on $\mathrm{SiO}_{2} / \mathrm{Si}$ substrates. The model provides data fittings with a MSE $\sim 6$. 
Table 2. Lorentz oscillators and pole parameters for reduced graphene oxide stabilized with poly(sodium 4-styrenesulfonate) on $\mathrm{SiO}_{2} / \mathrm{Si}$ substrates. Amplitude $A_{k}$ has a unit of $\mathrm{eV}^{2}$, center energy $E_{k}$ and broadening $\Gamma_{k}$ have units of eV; $d$ is the thickness of film in $\mathrm{nm}$; the high-frequency dielectric constant dielectric constant $\varepsilon_{\infty}$ is dimensionless.

\begin{tabular}{cc}
\hline \multicolumn{3}{c}{ PSS-RGO } \\
\hline$d(\mathrm{~nm})$ & $50 \pm 1$ \\
$\varepsilon_{\infty}$ & $1.01 \pm 0.01$ \\
$A_{1}\left(\mathrm{eV}^{2}\right)$ & $0.329 \pm 0.008$ \\
$\Gamma_{1}(\mathrm{eV})$ & $1.42 \pm 0.08$ \\
$E_{1}(\mathrm{eV})$ & $2.8 \pm 0.1$ \\
$A_{2}\left(\mathrm{eV}^{2}\right)$ & $383.6 \pm 16.3$ \\
$E_{2}(\mathrm{eV})$ & $9.6 \pm 0.2$ \\
\hline
\end{tabular}

As it can be seen in Table 2, the behavior of the dispersion laws of PSS-functionalized RGO films on $\mathrm{SiO}_{2} / \mathrm{Si}$ substrates is described by a Lorentz oscillator and a pole.

In the PSS-RGO optical model, oscillator 1 at $\sim 2.8 \mathrm{eV}$ may be assigned to novel states, which are originated by macro $\mathrm{sp}^{2}$ carbon sheet formation during reduction, because of the $\mathrm{sp}^{2}$ carbon network recovery [42]. Oscillator 2 is outside the ellipsometer's measurement range and therefore the pole function covers its contribution.

Figure 9 shows the dispersion laws, estimated by ellipsometry characterization in the $0.38-4.1 \mathrm{eV}$ photon energy range, of PSS-functionalized RGO films on $\mathrm{SiO}_{2} / \mathrm{Si}$ substrates.

These PSS-functionalized RGO films on $\mathrm{SiO}_{2} / \mathrm{Si}$ substrates could find use in several applications, for example sensors, due to their high transparency.

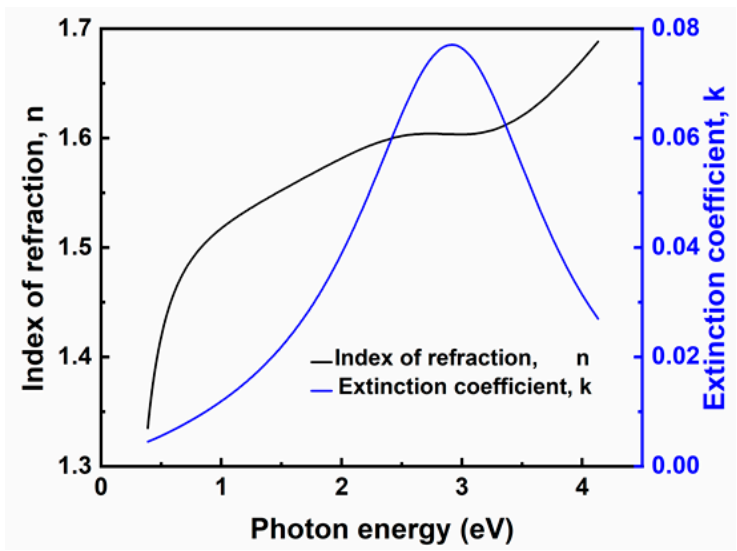

Figure 9. Estimated dispersion laws estimated of reduced graphene oxide stabilized with poly(sodium 4-styrenesulfonate) on $\mathrm{SiO}_{2} / \mathrm{Si}$ substrates by ellipsometry characterization. The curves represent the index of refraction (black lines) and the extinction coefficient (blue lines).

\section{Conclusions}

In conclusion, we have carried out VASE optical studies on GO films dip-coated on $\mathrm{SiO}_{2} / \mathrm{Si}$ that were eventually thermally reduced at $400{ }^{\circ} \mathrm{C}$ in the $0.38-4.1 \mathrm{eV}$ photon energy, which is interesting because in the near-infrared and mid-infrared range SE studies about GO-based materials are scarce.

The behavior of the dispersion laws of GO films is described using three Lorentz oscillators at around 2.8, 3.2, and $3.9 \mathrm{eV}$, while the dispersion laws of thermally reduced GO films were modeled using three Lorentz oscillators at around 2.1,3.17, and $4 \mathrm{eV}$.

In the GO optical model, oscillator 1 at $\sim 2.8 \mathrm{eV}$ denotes different coverage of mixed hydroxyl groups and oxygen atoms. Oscillator 2 at $\sim 3.2 \mathrm{eV}$ (at $\sim 388 \mathrm{~nm}$ ) represents a transition that is near the shoulder in the absorbance spectrum of GO (at $\sim 320 \mathrm{~nm}$ ) and close to the wavelength of blue 
luminescence detected for partially RGO (at $\sim 390 \mathrm{~nm}$ ). Oscillator 3 at $\sim 3.9 \mathrm{eV}$ is assigned to the small shoulder of GO in the absorbance spectrum.

In the RGO optical model, oscillator 1 at $\sim 2.1 \mathrm{eV}$ denotes different coverage of mixed hydroxyl groups and oxygen atoms. Oscillator 2 at $\sim 3.17 \mathrm{eV}$ is assigned to the narrow photoluminescence peak observed for partially RGO. Oscillator 3 at $\sim 4 \mathrm{eV}$ may be related to the absorption energy corresponding to the emission of blue light.

In addition, we report for the first time the optical properties of PSS-functionalized RGO films dip-coated on $\mathrm{SiO}_{2} / \mathrm{Si}$ in the same range.

The model of PSS-functionalized RGO films on $\mathrm{SiO}_{2} / \mathrm{Si}$ substrates is composed of a Lorentz oscillator at around $2.8 \mathrm{eV}$ and a pole. In the PSS-RGO optical model, oscillator 1 at $\sim 2.8 \mathrm{eV}$ may be assigned to novel states, which are originated by macro $\mathrm{sp}^{2}$ carbon sheet formation during reduction, because of the $\mathrm{sp}^{2}$ carbon network recovery.

Our GO, RGO, and PSS-RGO models provide accurate complex refractive index values that are useful especially in the extended near-infrared and mid-infrared spectral range, where they had not been reported before.

The results presented here may be beneficial for designing optical materials and components based on aqueous GO and PSS-RGO dispersion.

Author Contributions: Investigation, G.G.P., C.V. (Carlo Vena), G.D., and C.V. (Carlo Versace); supervision, C.V. (Carlo Versace); writing-original draft, G.G.P. and C.V. (Carlo Versace); writing-review and editing, G.G.P. and C.V. (Carlo Versace). All authors have read and agreed to the published version of the manuscript.

Funding: This research received no external funding.

Conflicts of Interest: The authors declare no conflict of interest.

\section{References}

1. Pei, S.; Cheng, H.-M. The reduction of graphene oxide. Carbon N. Y. 2012, 50, 3210-3228. [CrossRef]

2. Chua, C.K.; Pumera, M. Chemical reduction of graphene oxide: A synthetic chemistry viewpoint. Chem. Soc. Rev. 2014, 43, 291-312. [CrossRef] [PubMed]

3. Jung, I.; Dikin, D.A.; Piner, R.D.; Ruoff, R.S. Tunable Electrical Conductivity of Individual Graphene Oxide Sheets Reduced at "Low" Temperatures. Nano Lett. 2008, 8, 4283-4287. [CrossRef] [PubMed]

4. Aunkor, M.T.H.; Mahbubul, I.M.; Saidur, R.; Metselaar, H.S.C. The green reduction of graphene oxide. RSC Adv. 2016, 6, 27807-27828. [CrossRef]

5. Díaz, D.L.; Notario, J.D.; Clerico, V.; Diez, E.; Moreno, M.D.M.; Velázquez, M.M. Towards Understanding the Raman Spectrum of Graphene Oxide: The Effect of the Chemical Composition. Coatings 2020, 10, 524. [CrossRef]

6. Fernández, J.; Bonastre, J.; Molina, J.; Cases, F. Enhancement of the Electrochemical Properties of an Open-Pore Graphite Foam with Electrochemically Reduced Graphene Oxide and Alternating Current Dispersed Platinum Particles. Coatings 2020, 10, 551. [CrossRef]

7. Yuan, H.; Qi, F.; Zhao, N.; Wan, P.; Zhang, B.; Xiong, H.; Liao, B.; Ouyang, X. Graphene Oxide Decorated with Titanium Nanoparticles to Reinforce the Anti-Corrosion Performance of Epoxy Coating. Coatings 2020, 10, 129. [CrossRef]

8. Miao, X.; Xing, A.; He, L.; Meng, Y.; Li, X. One-Step Preparation of Hyperbranched Polyether Functionalized Graphene Oxide for Improved Corrosion Resistance of Epoxy Coatings. Coatings 2019, 9, 844. [CrossRef]

9. Nitu, F.; Burns, J.; Ionita, M. Oligonucleotide Detection and Optical Measurement with Graphene Oxide in the Presence of Bovine Serum Albumin Enabled by Use of Surfactants and Salts. Coatings 2020, 10, 420. [CrossRef]

10. Vlăsceanu, G.; Crica, L.; Pandele, A.; Ionita, M. Graphene Oxide Reinforcing Genipin Crosslinked Chitosan-Gelatin Blend Films. Coatings 2020, 10, 189. [CrossRef]

11. Domene-López, D.; Sarabia-Riquelme, R.; García-Quesada, J.; Martin-Gullon, I. Custom-Made Chemically Modified Graphene Oxide to Improve the Anti-Scratch Resistance of Urethane-Acrylate Transparent Coatings. Coatings 2019, 9, 408. [CrossRef] 
12. Muraru, S.; Samoila, C.-G.; Slusanschi, E.; Burns, J.; Ionita, M. Molecular Dynamics Simulations of DNA Adsorption on Graphene Oxide and Reduced Graphene Oxide-PEG-NH2 in the Presence of $\mathrm{Mg}^{2+}$ and $\mathrm{Cl}^{-}$ ions. Coatings 2020, 10, 289. [CrossRef]

13. Ren, X.; Li, J.; Chen, C.; Gao, Y.; Chen, D.; Su, M.; Alsaedi, A.; Hayat, T. Graphene analogues in aquatic environments and porous media: Dispersion, aggregation, deposition and transformation. Environ. Sci. Nano 2018, 5, 1298-1340. [CrossRef]

14. Li, J.; Miao, D.; Yang, R.; Qu, L.; Harrington, P. Synthesis of poly(sodium 4-styrenesulfonate) functionalized graphene/cetyltrimethylammonium bromide (CTAB) nanocomposite and its application in electrochemical oxidation of 2,4-dichlorophenol. Electrochim. Acta 2014, 125, 1-8. [CrossRef]

15. Li, J.; Zeng, L.; Ren, T.; van der Heide, E. The Preparation of Graphene Oxide and Its Derivatives and Their Application in Bio-Tribological Systems. Lubricants 2014, 2, 137-161. [CrossRef]

16. Yan, W.; Yu, W.-J.; Wang, L.; Zhang, D.; Ge, X.-Q.; Hang, J.-Z.; Deng, W.; Shi, L.-Y. Preparation of Partially Reduced Graphene Oxide Nanosheets/Poly(Sodium 4-Styrenesulfonate) Composite with High Capacitance. Electrochim. Acta 2014, 147, 257-264. [CrossRef]

17. Chen, J.; Liu, H.; Zhao, C.; Qin, G.; Xi, G.; Li, T.; Wang, X.; Chen, T. One-step reduction and PEGylation of graphene oxide for photothermally controlled drug delivery. Biomaterials 2014, 35, 4986-4995. [CrossRef] [PubMed]

18. Balamurugan, T.; Berchmans, S. Non-enzymatic detection of bilirubin based on a graphene-polystyrene sulfonate composite. RSC Adv. 2015, 5, 50470-50477. [CrossRef]

19. Wang, Y.; Liu, K.; Luo, Z.; Duan, Y. Preparation and tumor cell model based biobehavioral evaluation of the nanocarrier system using partially reduced graphene oxide functionalized by surfactant. Int. J. Nanomed. 2015, 10, 4605-4620. [CrossRef]

20. Miyazaki, C.M.; Maria, M.A.E.; Borges, D.D.; Woellner, C.F.; Brunetto, G.; Fonseca, A.F.; Constantino, C.J.L.; Pereira-da-Silva, M.A.; de Siervo, A.; Galvao, D.S.; et al. Experimental and computational investigation of reduced graphene oxide nanoplatelets stabilized in poly(styrene sulfonate) sodium salt. J. Mater. Sci. 2018, 53, 10049-10058. [CrossRef]

21. Tompkins, H.; Irene, E.A. Handbook of Ellipsometry; William Andrew: Norwich, NY, USA, 2005.

22. Politano, G.G.; Cazzanelli, E.; Versace, C.; Vena, C.; de Santo, M.P.; Castriota, M.; Ciuchi, F.; Bartolino, R. Graphene oxide on magnetron sputtered silver thin films for SERS and metamaterial applications. Appl. Surf. Sci. 2018, 427. [CrossRef]

23. Politano, G.G.; Vena, C.; Desiderio, G.; Versace, C. Spectroscopic ellipsometry investigation of the optical properties of graphene oxide dip-coated on magnetron sputtered gold thin films. J. Appl. Phys. 2018, 123. [CrossRef]

24. Politano, G.G.; Versace, C.; Vena, C.; Castriota, M.; Ciuchi, F.; Fasanella, A.; Desiderio, G.; Cazzanelli, E. Physical investigation of electrophoretically deposited graphene oxide and reduced graphene oxide thin films. J. Appl. Phys. 2016, 120, 195307. [CrossRef]

25. Politano, G.G.; Nucera, A.; Castriota, M.; Desiderio, G.; Vena, C.; Versace, C. Spectroscopic and morphological study of graphene nanoplatelets thin films on $\mathrm{Si} / \mathrm{SiO} 2$ substrates. Mater. Res. Express 2019, 6, 106432. [CrossRef]

26. Woollam, J.A.; Hilfiker, J.N.; Bungay, C.L.; Synowicki, R.A.; Tiwald, T.E.; Thompson, D.W. Spectroscopic ellipsometry from the vacuum ultraviolet to the far infrared. AIP Conf. Proc. 2001, 550, 511-518. [CrossRef]

27. Woollam, J.A.; Johs, B.D.; Herzinger, C.M.; Hilfiker, J.N.; Synowicki, R.A.; Bungay, C.L. Overview of variable-angle spectroscopic ellipsometry (VASE): I. Basic theory and typical applications. In Proceedings of the SPIE's International Symposium on Optical Science, Engineering, and Instrumentation, Denver, CO, USA, 18-23 July 1999; The International Society for Optical Engineering: Denver, CO, USA, 1999.

28. Shen, Y.; Zhou, P.; Sun, Q.Q.; Wan, L.; Li, J.; Chen, L.Y.; Zhang, D.W.; Wang, X.B. Optical investigation of reduced graphene oxide by spectroscopic ellipsometry and the band-gap tuning. Appl. Phys. Lett. 2011, 99. [CrossRef]

29. Schöche, S.; Hong, N.; Khorasaninejad, M.; Ambrosio, A.; Orabona, E.; Maddalena, P.; Capasso, F. Optical properties of graphene oxide and reduced graphene oxide determined by spectroscopic ellipsometry. Appl. Surf. Sci. 2017. [CrossRef]

30. Chang, Y.-C.; Liu, C.-H.; Liu, C.-H.; Zhang, S.; Marder, S.R.; Narimanov, E.E.; Zhong, Z.; Norris, T.B. Realization of mid-infrared graphene hyperbolic metamaterials. Nat. Commun. 2016, 7, 10568. [CrossRef] 
31. Popa, D.; Udrea, F. Towards Integrated Mid-Infrared Gas Sensors. Sensors 2019, 19, 2076. [CrossRef]

32. Kravets, V.G.; Marshall, O.P.; Nair, R.R.; Thackray, B.; Zhukov, A.; Leng, J.; Grigorenko, A.N. Engineering optical properties of a graphene oxide metamaterial assembled in microfluidic channels. Opt. Express 2015, 23, 1265-1275. [CrossRef]

33. Li, G.; Liu, L.; Wu, G.; Chen, W.; Qin, S.; Wang, Y.; Zhang, T. Self-Powered UV-Near Infrared Photodetector Based on Reduced Graphene Oxide/n-Si Vertical Heterojunction. Small 2016, 12, 5019-5026. [CrossRef] [PubMed]

34. Scriven, L.E. Physics and Applications of DIP Coating and Spin Coating. MRS Proc. 1988, 121, 717. [CrossRef]

35. Hortigüela, J.M.; Machado, D.; Bdikin, I.; Neto, V.; Otero-Irurueta, G. Chemical Changes of Graphene Oxide Thin Films Induced by Thermal Treatment under Vacuum Conditions. Coatings 2020, 10, 113. [CrossRef]

36. J.A. Woollam Co. Inc. WVASE Manual "Guide to Using WVASE32"; Woollam Co.: Lincon, NE, USA, 2010.

37. Kubo, R.; Ichimura, M. Kramers-Kronig Relations and Sum Rules. J. Math. Phys. 1972, 13, $1454-1461$. [CrossRef]

38. Boukhvalov, D.W.; Katsnelson, M.I. Modeling of Graphite Oxide. J. Am. Chem. Soc. 2008, 130, $10697-10701$. [CrossRef]

39. Bansal, T.; Mohite, A.D.; Shah, H.M.; Galande, C.; Srivastava, A.; Jasinski, J.B.; Ajayan, P.M.; Alphenaar, B.W. New insights into the density of states of graphene oxide using capacitive photocurrent spectroscopy. Carbon N. Y. 2012, 50, 808-814. [CrossRef]

40. Eda, G.; Lin, Y.-Y.; Mattevi, C.; Yamaguchi, H.; Chen, H.-A.; Chen, I.-S.; Chen, C.-W.; Chhowalla, M. Blue Photoluminescence from Chemically Derived Graphene Oxide. Adv. Mater. 2010, 22, 505-509. [CrossRef]

41. Yakuphanoglu, F.; Sekerci, M.; Ozturk, O.F. The determination of the optical constants of Cu(II) compound having 1-chloro-2,3-o-cyclohexylidinepropane thin film. Opt. Commun. 2004, 239, 275-280. [CrossRef]

42. Liang, H.F.; Smith, C.T.G.; Mills, C.A.; Silva, S.R.P. The band structure of graphene oxide examined using photoluminescence spectroscopy. J. Mater. Chem. C 2015, 3, 12484-12491. [CrossRef]

(C) 2020 by the authors. Licensee MDPI, Basel, Switzerland. This article is an open access article distributed under the terms and conditions of the Creative Commons Attribution (CC BY) license (http://creativecommons.org/licenses/by/4.0/). 